\title{
Enamine Carboxylates as Stereodetermining Intermediates in Prolinate Catalysis
}

DOI:

10.1021/ol2023533

Link to publication record in Manchester Research Explorer

\section{Citation for published version (APA):}

Hein, J. E., Burés, J., Lam, Y., Hughes, M., Houk, K. N., Armstrong, A., \& Blackmond, D. G. (2011). Enamine Carboxylates as Stereodetermining Intermediates in Prolinate Catalysis. Organic Letters, 13, 5644-5647. https://doi.org/10.1021/ol2023533

\section{Published in:}

Organic Letters

\section{Citing this paper}

Please note that where the full-text provided on Manchester Research Explorer is the Author Accepted Manuscript or Proof version this may differ from the final Published version. If citing, it is advised that you check and use the publisher's definitive version.

\section{General rights}

Copyright and moral rights for the publications made accessible in the Research Explorer are retained by the authors and/or other copyright owners and it is a condition of accessing publications that users recognise and abide by the legal requirements associated with these rights.

\section{Takedown policy}

If you believe that this document breaches copyright please refer to the University of Manchester's Takedown Procedures [http://man.ac.uk/04Y6Bo] or contact uml.scholarlycommunications@manchester.ac.uk providing relevant details, so we can investigate your claim.

\section{OPEN ACCESS}




\title{
Enamine Carboxylates as Stereodetermining Intermediates in Prolinate Catalysis
}

2011

Vol. 13, No. 20

$5644-5647$

\author{
Jason E. Hein, ${ }^{\dagger}$ Jordi Burés, ${ }^{\dagger}$ Yu-hong Lam, ${ }^{\ddagger}$ Matthew Hughes, ${ }^{\S}$ K. N. Houk, ${ }^{*, \ddagger}$ Alan \\ Armstrong, ${ }^{*, \S}$ and Donna G. Blackmond ${ }^{*, \dagger}$ \\ Department of Chemistry, The Scripps Research Institute, La Jolla, California 92037, \\ United States, Department of Chemistry, UCLA, Los Angeles, California 90095, United \\ States, and Department of Chemistry, Imperial College, London SW7 2AZ, U.K.
}

houk@chem.ucla.edu; a.armstrong@imperial.ac.uk; blackmond@scripps.edu

Received September 1, 2011

ABSTRACT

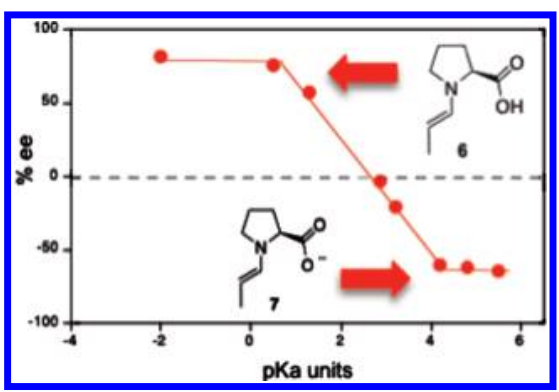

Experimental and computational studies probing the nature of intermediates in the $\alpha$-amination of aldehydes catalyzed by prolinate salts support an enamine carboxylate intermediate in the stereodetermining step.

Proline-mediated reactions between carbonyl compounds and electrophiles represent a central paradigm for stereoselectivity in aminocatalysis. ${ }^{1}$ The Houk-List transition state model $^{2}$ invoking an interaction between the carboxyl proton and the incoming electrophile (TS-A) has successfully rationalized a wide range of results. Seebach and Eschenmoser ${ }^{3}$ have presented a separate model

${ }^{\dagger}$ The Scripps Research Institute.

UCLA.

${ }^{\S}$ Imperial College.

(1) (a) List, B.; Lerner, R. A.; Barbas, C. F. J. Am. Chem. Soc. 2000, 122, 2395. (b) Mukherjee, S.; Yang, J. W.; Hoffmann, S.; List, B. Chem. Rev. 2007, 107, 5471. (c) Melchiorre, P.; Marigo, M.; Carlone, A.; Bartoli, G. Angew. Chem., Int. Ed. 2008, 47, 6138. (d) Bertelsen, S.; Jørgensen, K. A. Chem. Soc. Rev. 2009, 38, 2178.

(2) (a) Bahmanyar, S.; Houk, K. N. J. Am. Chem. Soc. 2001, 123, 11273. (b) Bahmanyar, S.; Houk, K. N.; Martin, H. J.; List, B. J. Am. Chem. Soc. 2003, 125, 2475. (c) Cheong, P. H. Y.; Houk, K. N. Synthesis 2005, 1533. (d) Hoang, L.; Bahmanyar, S.; Houk, K. N.; List, B. J. Am. Chem. Soc. 2003, 125, 16. (e) List, B.; Hoang, L.; Martin, H. J.Proc. Natl.Acad.Sci.U.S.A. 2004, 101, 5839. (f) Clemente, F. R.; Houk, K. N. Angew. Chem. Int. Ed. 2004, 43, 5766.

(3) Seebach, D.; Beck, A. K.; Badine, D. M.; Limbach, M.; Eschenmoser, A.; Treasurywala, A. M.; Hobi, R.; Prikoszovich, W.; Linder, B. Helv. Chim. Acta 2007, 90, 425. highlighting a role for oxazolidinone species and carboxylate anions, with stereoinduction in the same sense as in the Houk-List model (TS-B). However, a reassessment of that proposal was necessitated by Blackmond and Armstrong's report ${ }^{4}$ of a reversal of enantioselectivity in $\alpha$ amination reactions catalyzed by proline in the presence of tertiary amine bases or by preformed prolinate salts (Scheme 1). This result was rationalized by invoking preferential formation of the anti enamine and attack on the electrophile from the face opposite the carboxylate group (TS-C), in line with the steric model introduced for reactions using bulky proline derivatives such as diarylprolinol ethers. ${ }^{5}$ Sharma and Sunoj ${ }^{6}$ provided computational support for pathway TS-C to account for the

(4) Blackmond, D. G.; Moran, A.; Hughes, M.; Armstrong, A. J. Am. Chem. Soc. 2010, 132, 7598 .

(5) (a) Franzen, J.; Marigo, M.; Fielenbach, D.; Wabnitz, T. C.; Kjærsgaard, A.; Jørgensen, K. A. J. Am. Chem. Soc. 2005, 127, 18296. (b) Hayashi, Y.; Gotoh, H.; Hayashi, T.; Shoji, M. Angew. Chem.. Int. Ed. 2005, 44, 4212 .

(6) (a) Sharma, A. K.; Sunoj, R. B. Angew. Chem. Int. Ed. 2010, 49 , 6373. (b) Sharma, A. K.; Sunoj, R. B. Chem. Commun. 2011, 47, 5740. 
observed reversal in configuration. We report here NMR and computational studies to shed further light on the nature of the intermediates in proline-based aminocatalysis in the presence and absence of acids and bases. The effects on the stereochemical outcome in $\alpha$-amination using prolinate catalysts of acid and base $\mathrm{p} K_{\mathrm{a}}$ as well as of the prolinate counterion are discussed in terms of these models.

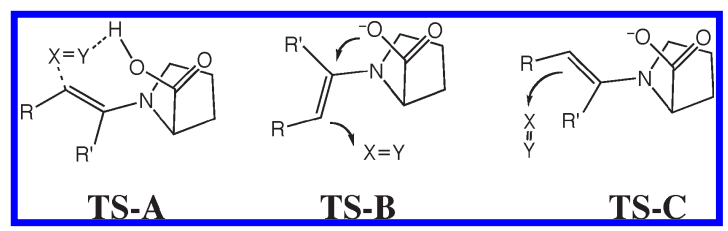

Scheme 1. $\alpha$-Amination of Propanal ${ }^{4}$

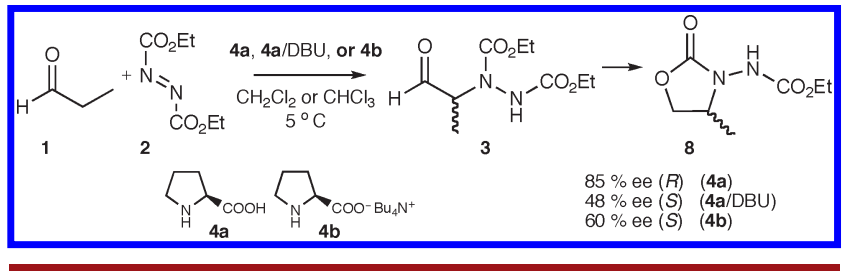

Enamines as intermediates are key to all of these models, but quantitative experimental identification of such species remained elusive until the recent work of Gschwind ${ }^{7}$ demonstrating the power of NMR exchange spectroscopy (EXSY), providing the first detailed characterization of intermediates in the proline-mediated self-aldol reaction of propanal in DMSO as solvent. This work may be considered as a breakthrough in mechanistic aminocatalysis, showing how the detection and temporal monitoring of intermediates augment kinetic, computational, and other mechanistic tools.

Because the $\alpha$-amination reactions of propanal in which we observed the reversal of enantioselectivity for prolinate vs proline catalysts were carried out in chlorinated hydrocarbon solvents, we performed NMR spectroscopic studies to probe the interaction of propanal $\mathbf{1}$ with catalysts $\mathbf{4 a}$ and $\mathbf{4 b}$ in $\mathrm{CDCl}_{3}$. The Gschwind work did not study these solvents but concluded that proline enamines are stabilized by a combination of low H-bond donor $(\alpha)$ and high H-bond acceptor $(\beta)$ solvent properties. ${ }^{8}$ This allows the prediction that oxazolidinone species should dominate over enamines for the propanal/proline interaction in $\mathrm{CH}_{2} \mathrm{Cl}_{2}$ and $\mathrm{CHCl}_{3}$. Figure 1 a confirms that the diastereomeric oxazolidinone species $\mathbf{5 a}$ and $\mathbf{5 b}$ are the major species formed from $\mathbf{1}$ and $\mathbf{4 a}$ in $\mathrm{CDCl}_{3}$ in a ratio similar to that observed in DMSO. ${ }^{7}$ 1D-EXSY shows that $\mathbf{5 a}$ and $\mathbf{5 b}$ are in rapid chemical exchange with each other and with $\mathbf{1} .{ }^{9}$

(7) (a) Schmid, M. B.; Zeitler, K.; Gschwind, R. M. Angew. Chem. Int. Ed. 2010, 49, 4997. (b) Schmid, M. B.; Zeitler, K.; Gschwind, R. M. Chem. Sci. 2011, 2, 1793.

(8) Abraham, M. H.; Platts, J. A. J. Org. Chem. 2001, 66, 3484.

(9) See Supporting Information.
No enamine species $\mathbf{6}$ are detectable even at high concentrations. ${ }^{\text {? }}$

When propanal reacts with $4 \mathbf{4} / \mathrm{DBU}$ or with the prolinate salt $\mathbf{4 b}$ in $\mathrm{CDCl}_{3}$, however, the enamine carboxylate 7 is the major intermediate species, with oxazolidinones either absent or present at concentrations lower than the detection limit (Figure 1b). EXSY studies show that the enamine is in rapid chemical exchange with the aldehyde, contrary to Gschwind's observation for the prolinepropanal reaction in DMSO. ${ }^{7}$
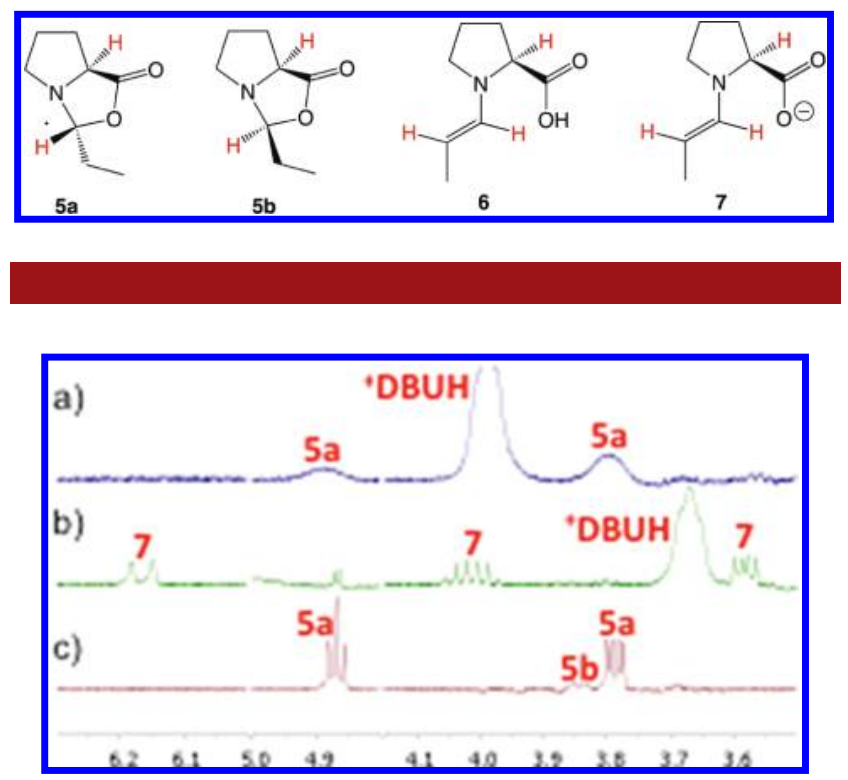

Figure 1. ${ }^{1} \mathrm{H}$ NMR spectra of 10 equiv of 1 in $\mathrm{CDCl}_{3}$ with 1 equiv of (a) $4 a$, (b) $4 a / D B U$, and (c) $4 a / D B U+1$ equiv of $\mathrm{CH}_{3} \mathrm{COOH}$.

We turned to theoretical calculations to help rationalize these kinetic and spectroscopic results. The computed gasphase structures and energies of $\mathbf{5} \mathbf{a}$ and $\mathbf{5 b}$ confirm the oxazolidinone exo/endo ratio observed experimentally in both DMSO and chlorinated hydrocarbon solvents. 9 However, proline enamine $\mathbf{6}$ was predicted to be ca. $10 \mathrm{kcal} / \mathrm{mol}$ higher in energy than $\mathbf{5 a}$ or $\mathbf{5 b}$ by computations in the gas phase or using an implicit solvation model. This energy difference agrees with our experimental results in $\mathrm{CDCl}_{3}$ but is too large to account for the ratio of oxazolidinones to enamine found in DMSO (91:9) by Gschwind. ${ }^{7}$ Modeling the solvent as a constant-dielectric continuum is inadequate to account for solvent effects in determining the oxazolidinone/enamine equilibrium. However, explicit inclusion of one DMSO molecule with 6 leads to significant stabilization with respect to the corresponding oxazolidinone complex, as the free energy difference is substantially reduced to only $0.6 \mathrm{kcal} / \mathrm{mol}$ (Figure $2 \mathrm{a}$ ). By contrast, the corresponding solvent inclusion calculation for $\mathrm{CH}_{2} \mathrm{Cl}_{2}$ showed little stabilization of $\mathbf{6}$ with respect to 5 (Figure 2b), rationalizing the dominance of 5 over $\mathbf{6}$ in chlorinated solvents. The experimental finding that the enamine carboxylate 7 is more stable than oxazolidinones $\mathbf{5 a}$ and $\mathbf{5 b}$ for $\mathbf{4 a}$ in the presence of a base is supported by calculations showing that this conversion is thermodynamically favorable by $5.7 \mathrm{kcal} / \mathrm{mol}$ (Figure 2c). 
NMR studies show that oxazolidinones $\mathbf{5 a}$ and $\mathbf{5 b}$ derived from $\mathbf{1}$ and $\mathbf{4 a}$ in $\mathrm{CDCl}_{3}$ are converted quantitatively to the enamine carboxylate species 7 by addition of base to the proline-propanal system, as has also been shown by Seebach. ${ }^{3}$ Addition of 1 equiv of acetic acid to 1 and $\mathbf{4 b}$ or $\mathbf{1}$ and $\mathbf{4 a} / \mathrm{DBU}$ quantitatively shifts the dominant population from $\mathbf{7}$ back to $\mathbf{5} \mathbf{a}$ and $\mathbf{5 b}$ (Figure 1c). Intriguingly, the reversal in the sense of product stereochemistry in the $\alpha$-amination reaction of Scheme 1 using either $\mathbf{4 a}$ / DBU or $\mathbf{4 b}$ as catalyst compared to $\mathbf{4 a}$ is observed in both the absence of acid, where 7 is the dominant intermediate, and the presence of 1 equiv acetic acid, where $\mathbf{5} \mathbf{a}$ and $\mathbf{5} \mathbf{b}$ are dominant (Scheme 2, Table 1).

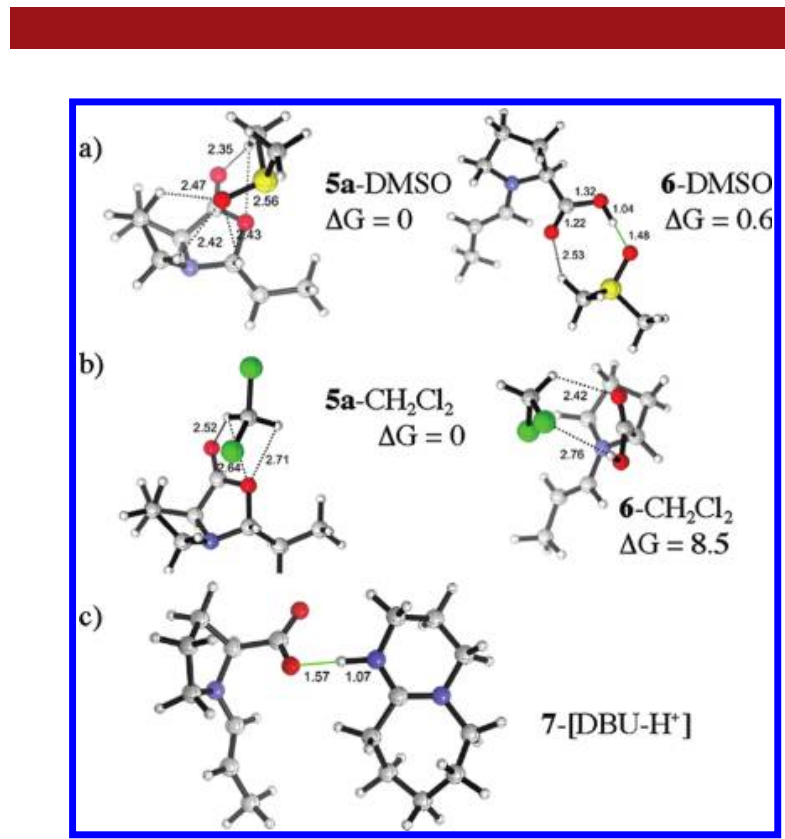

Figure 2. Optimized structures and relative energies computed by M06-2X/6-31+G(d,p) for (a) 5a and $\mathbf{6}$ as 1:1 DMSO complexes; (b) $5 \mathbf{a}$ and $\mathbf{6}$ as 1:1 $\mathrm{CH}_{2} \mathrm{Cl}_{2}$ complexes; and (c) 7 as a 1:1 $\left[\mathrm{DBU}-\mathrm{H}^{+}\right]$complex.

These experimental results demonstrate the ease of interconversion between enamine 7 and oxazolidinones $\mathbf{5 a}$ and $\mathbf{5 b}$ by simple acid/base manipulation. Scheme 2 suggests that the relative stability of these species in the reaction mixture for a particular catalyst is not correlated with the product stereochemistry observed in the amination reaction. This contradicts a previous suggestion that the relative availability of enamine vs oxazolidinone species might be key to the stereochemical outcome of reactions with electrophiles, ${ }^{6 a}$ as well as the proposal that a correlation may be made between lower enamine concentrations (or reduced rates of enamine formation) and lower catalytic activity for various pyrrolidine-based catalysts. ${ }^{11,10}$ In fact, the rate of electrophile addition, measured by the propionaldehyde self-aldol reaction, is similar for $\mathbf{4 a} / \mathrm{DBU}+$ acid, which exhibits a very low enamine

(10) Schmid, M. B.; Zeitler, K.; Gschwind, R. M. J. Am. Chem. Soc. 2011, 133, 7065 .

(11) Kanzian, T.; Lakhdar, S.; Mayr, H. Angew. Chem. Int. Ed. 2010, 49,9526
Scheme 2. Observed (Highlighted) and Reactive Species

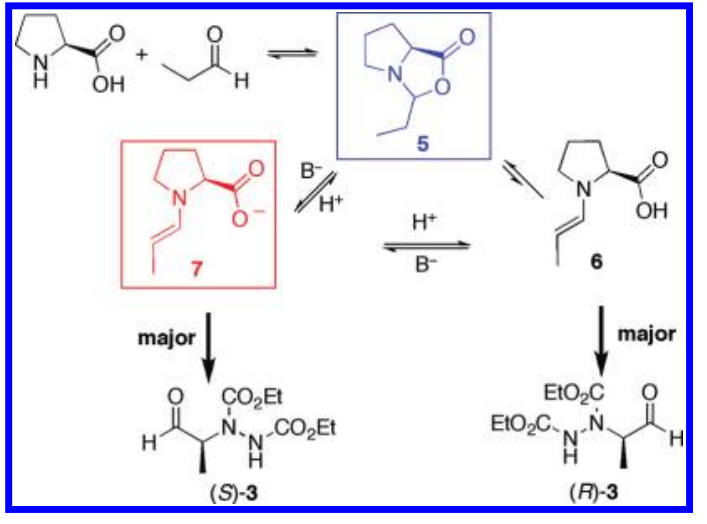

Table 1. Effect of Acids in the Reaction of Scheme $1^{a}$

\begin{tabular}{|c|c|c|c|c|}
\hline entry & catalyst & additive (aqueous $\mathrm{p} K_{\mathrm{a}}$ ) & $\begin{array}{c}8 \text { yield } \\
(\%)\end{array}$ & $\begin{array}{l}8 \text { ee } \\
(\%)\end{array}$ \\
\hline 1 & $4 a$ & none & 75 & $85(R)$ \\
\hline 2 & 4a/DBU & none & 71 & $48(S)$ \\
\hline 3 & $\mathbf{4 a} / \mathrm{DBU}$ & 1 equiv $\mathrm{CH}_{3} \mathrm{COOH}$ (4.8) & 68 & $52(S)$ \\
\hline 4 & $4 b$ & none & 72 & $66(S)$ \\
\hline 5 & $4 b$ & 1 equiv $\mathrm{CH}_{3} \mathrm{COOH}$ (4.8) & 79 & $62(S)$ \\
\hline 6 & $4 b$ & 5 equiv $\mathrm{CH}_{3} \mathrm{COOH}$ (4.8) & 73 & $31(S)$ \\
\hline 7 & $4 b$ & $\mathrm{NBu}_{4} \mathrm{HSO}_{4}(5.5)$ & n.m. & $65(S)$ \\
\hline 8 & $4 b$ & $\mathrm{PhCH}_{2} \mathrm{COOH}$ (4.2) & n.m. & $62(S)$ \\
\hline 9 & $4 b$ & 2-I- $\mathrm{C}_{6} \mathrm{H}_{4} \mathrm{CH}_{2} \mathrm{COOH}$ (3.2) & n.m. & $21(S)$ \\
\hline 10 & $4 b$ & $\mathrm{CH}_{2} \mathrm{ClCOOH}$ (2.9) & n.m. & $3(S)$ \\
\hline 11 & $4 b$ & $\mathrm{CHCl}_{2} \mathrm{COOH}(1.3)$ & n.m. & $57(R)$ \\
\hline 12 & $4 b$ & $\mathrm{CF}_{3} \mathrm{COOH}(0.5)$ & n.m. & $76(R)$ \\
\hline 13 & $4 b$ & $\mathrm{CH}_{3} \mathrm{SO}_{3} \mathrm{H}(-2.0)$ & n.m. & $81(R)$ \\
\hline
\end{tabular}

concentration, and 4a/DBU, which exhibits a very high enamine concentration, and both exhibit much higher rates than $\mathbf{4 a}$, which exhibits a very low enamine concentration (eqs 1 and 2). This confirms that not only the population of the reactive species but also its intrinsic reactivity must be considered in such comparisons.

Enamine $(\mathbf{6}$ or 7$)$ concentration:
$\mathbf{4 a} / \mathrm{DBU}>\mathbf{4 a} / \mathrm{DBU} / \mathrm{CH}_{3} \mathrm{COOH} \approx \mathbf{4 a}$
Rate of self-aldol reaction:
$\mathbf{4 a} / \mathrm{DBU} \approx \mathbf{4 a} / \mathrm{DBU} / \mathrm{CH}_{3} \mathrm{COOH}>\mathbf{4 a}$

Addition of more than 1 equiv of acetic acid, or use of 1 equiv of stronger acids, shifts product selectivity in reactions using $\mathbf{4 a} / \mathrm{DBU}$ or $\mathbf{4 b}$ back to that observed with proline $\mathbf{4 a}$, as shown in Table 1.

Nearly racemic product was observed for the reaction carried out with 1 equiv of added chloroacetic acid, which has a $\mathrm{p} K_{\mathrm{a}}=2.86$, a value close to that of the proline carboxyl proton (eq 3). This suggests that under these conditions the system consists of a mixture of proline and 
prolinate intermediates competitively inducing product stereochemistry opposite to the other.

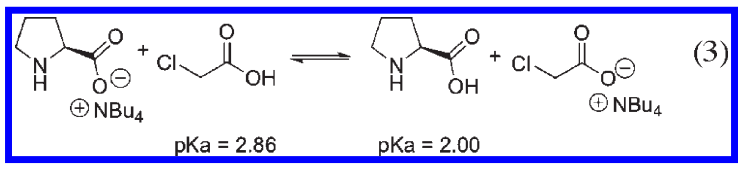

These results indicate that the stereochemical outcome is controlled by the relative dominance of proline vs prolinate and that the distribution between the two intermediates in the presence of acids and bases in $\mathrm{CH}_{2} \mathrm{Cl}_{2}$ follows the same trends as aqueous $\mathrm{p} K_{\mathrm{a}}$ values. However, the suggestion ${ }^{6 \mathrm{~b}}$ of the coexistence of enamine $\mathbf{6}$ and enamine carboxylate 7 from 4/DBU in the absence of added acid is not likely, since our previous reaction results ${ }^{4}$ suggest that proline remains fully deprotonated in the presence of 1 equiv of DBU in chlorinated solvents. Comparison of the NMR spectra of $\mathbf{4 a}$ and preformed $\mathbf{4 b}$ with those of $4 \mathrm{a} / \mathrm{DBU}$ in the presence and absence of added acid supports this conclusion. ${ }^{9}$

In addition to acid strength, we explored the effect of counterion size on the reversal of enantioselectivity achieved with prolinate catalysts. The entries in Table 2 show results for reactions with catalysts prepared in situ from proline mixed in a 1:1 ratio with a variety of acetate salts. Inversion of selectivity compared to proline was observed in all cases with a clear trend between counterion size and product ee. We previously observed that metal prolinates afford racemic products in this reaction, but addition of crown ethers again leads to formation of inverted products $\left(55-65 \%\right.$ ee), albeit with low yields. ${ }^{9}$ This provides another potential approach for catalyst tuning. All of these results support our previous observation that attack on the enamine proceeds with opposite facial selectivity in systems lacking proline's carboxyl proton. However, these results cannot distinguish unequivocally between the proposal of a covalent carboxylate interaction forming the product oxazolidinone ${ }^{3}$ and that of a steric blocking effect as has been proposed for diarylprolinol ether catalysts. $5,11,12$

In summary, we have provided the first spectroscopic characterization of the enamine carboxylate intermediates

(12) (a) Fu, A.; List, B.; Thiel, W. J. Org. Chem. 2006, 71, 320. (b) Bock, D. A.; Lehmann, C. W.; List, B. Proc. Natl. Acad. Sci. U.S.A. 2010, 107, 20636.
Table 2. Effect of Counterion on Product Enantioselectivity

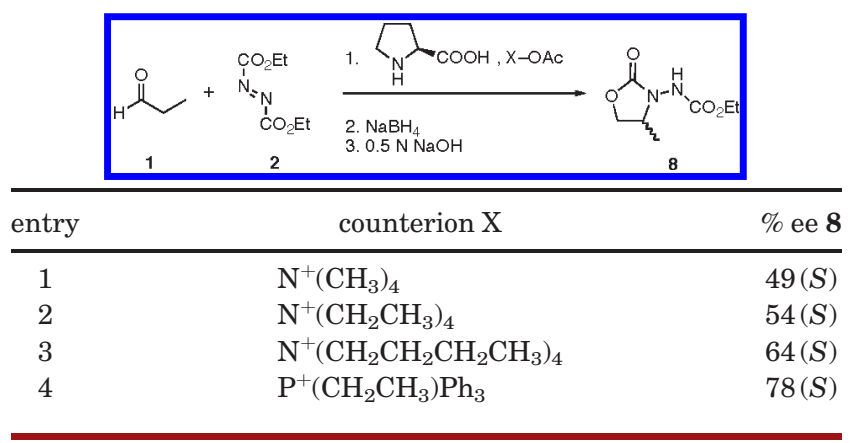

that play a role in the inversion of enantioselectivity observed in the $\alpha$-amination of aldehydes catalyzed by proline in the presence of an organic base. These studies provide a basis for understanding the experimentally observed equilibria and interconversion between two key classes of intermediates, enamines, and oxazolidinones. The oxazolidinone of propanal may be observed in both the presence and absence of organic base, and its relative concentration is not related to the stereochemical outcome of the reaction. ${ }^{13}$ The observed effects of acid and counterion on enantiomeric excess help to rationalize the switch between stereoselectivity dictated by the carboxyl protondirected Houk-List model and by the enamine carboxylate system. The computational study provides support for Gschwind's rationalization of enamine concentration based on solvent $\mathrm{H}$-bond acceptor properties. The importance of $\mathrm{H}$-bonding in stabilizing organocatalytic intermediates is highlighted, demonstrating the significance of specific solute-solvent interactions in the transition state modeling in aminocatalysis in general.

Acknowledgment. Funding from the EPSRC and The Scripps Research Institute is gratefully acknowledged.

Supporting Information Available. Experimental procedures and details of the NMR measurements. This material is available free of charge via the Internet at http://pubs.acs.org.

(13) Landis, C. R.; Halpern, J. A. J. Am. Chem.Soc. 1987, 109, 1746. 